\title{
Crescimento Econômico e Restrições Externas na América Latina e Caribe: uma Análise Baseada em Dados em Painel
}

\section{Economic Growth and the Balance-of-Payments Constraint in Latin America and Caribbean: a Panel Data Analysis}

Resumo: O presente estudo tem o objetivo de verificar empiricamente a relação entre o comércio internacional e o crescimento econômico da América Latina e do Caribe no período recente, sob a óptica do modelo de Thirlwall. Mais especificamente, procura-se testar de forma empírica o modelo de Thirlwall utilizando técnicas para dados em painel, como forma de se controlar a heterogeneidade das economias de cada país da região. Os resultados mostraram que a taxa de crescimento da América Latina e do Caribe compatível com equilíbrio na balança comercial é de aproximadamente 3\% anuais, um patamar que, embora seja superior ao crescimento médio das economias da região observado no período, considera-se excessivamente baixo para que os seus países possam superar suas condições de subdesenvolvimento. Além disso, embora a elasticidade-renda das importações tenha se comportado estavelmente nas últimas décadas, houve uma tendência autônoma de elevação da demanda por importações na região a partir da década de 1990.

Palavras-chave: Lei de Thirlwall. Macroeconomia aberta. Modelos de dados em painel. América Latina.

Abstract: The main focus of this paper is to assess the relationship between international trade and economic growth in Latin America and the Caribbean for the period 1980-2005. We use panel data models to test Thirlwall's law. Our results show that a growth rate of about $3 \%$ per year is compatible with foreign

Pesquisador associado do International Policy Centre for Inclusive Growth (IPC-IG), órgão subordinado ao United Nations Development Programme (UNDP). Mestre em Economia pelo Centro de Desenvolvimento e Planejamento Regional da Universidade Federal de Minas Gerais (CEDEPLAR-UFMG). O autor agradece as contribuições de Fabrício Vieira e da Profa. Dra. Flávia Chein (CEDEPLAR-UFMG) para a elaboração deste trabalho. E-mail: ricardoamartini@gmail.com 
trade equilibrium. Although this rate is above the average growth observed in the period, it is not sufficient to allow the countries in the region to overcome its current stage of socio-economical underdevelopment. We also show that despite the stability of the income-elasticity of imports in the last decades, there has been an autonomous rise in the demand for imports in the region from the 1990s onwards.

Keywords: Thirlwall's Law. Open macroeconomics. Panel data models. Latin America.

JEL Classification: C23; E12; F43; O54.

\section{1 lntrodução}

A preocupação com o papel do setor externo para o crescimento esteve presente nas diretrizes de política econômica em todo o desenvolvimento histórico dos países latino-americanos e caribenhos (CARDOSO; HELWEGE, 1993). Até a década de 1930, o setor primário-exportador era o carro-chefe do dinamismo econômico em praticamente todas as economias da região. Por outro lado, desde a década de 1930 até meados da década de 1980, esses países mantiveram um modelo de desenvolvimento econômico fechado, baseado no protecionismo e na produção para o mercado interno. A partir dos anos oitenta, no entanto, esse modelo entrou em uma grave crise, que restringiu o crescimento econômico da região durante cerca de uma década. Em 1989, uma reunião de instituições econômicas internacionais foi realizada em Washington (EUA), na qual foi recomendada uma série de políticas liberalizantes para a América Latina e o Caribe, de modo a recuperar a trajetória de crescimento pelo estímulo às exportações e aos investimentos privados, e propiciar uma melhor alocação de recursos em suas economias nacionais, em detrimento das ineficiências acumuladas pelo excesso de proteção nas décadas anteriores (WILLIAMSON, 2004).

Durante a década de noventa, os países da região adotaram políticas nesse sentido, em maior ou menor grau. Contudo, é tema de estudos e controvérsias a possibilidade da demanda por importações na América Latina crescer com maior intensidade ao longo do tempo do que a demanda externa por suas exportações, de modo que os países venham a atravessar constantes desequilíbrios comerciais, o que provocaria a tomada de políticas corretivas, contracionistas de demanda, que restringiriam o crescimento. Nesse sentido, aplicações empíricas do modelo de Thirlwall (MCCOMBIE; THIRLWALL, 1994) para a região são cada vez mais populares entre os pesquisadores. Segundo essa teoria, a taxa de crescimento de equilíbrio de um país é uma taxa de cresci- 
mento compatível com o equilíbrio de sua balança de pagamentos, determinado, por sua vez, pelas elasticidades-renda das importações e exportações do país.

O objetivo do presente trabalho é estimar o modelo de Thirlwall de modo a testar empiricamente a relação entre comércio internacional e crescimento econômico na América Latina e no Caribe desde a década de oitenta até a atualidade. Para isso, procurar-se-á estimar as elasticidades presentes no modelo como se fossem agregados para toda a região, utilizando-se e comparando-se diferentes métodos econométricos. A importância de se estudar empiricamente essas elasticidades para a região como um todo, e não meramente para países individuais, decorre de quatro fatores principais. Em primeiro lugar, os países da região, ainda que possuam características econômicas estruturais distintas, compartilham um contexto histórico e institucional semelhante no que diz respeito ao papel do setor externo para o crescimento de suas economias, tal como apresentado nos parágrafos anteriores. Em segundo lugar, a teoria de Thirlwall, mais do que um modelo de crescimento, é uma teoria do desenvolvimento econômico, já que parte do pressuposto de que a restrição externa provocada por uma alta elasticidade-renda da demanda por importações é um fator que prejudica o crescimento dos países subdesenvolvidos. Assim, para a América Latina e Caribe, regiões povoadas por economias subdesenvolvidas ou em desenvolvimento, é esperado que os resultados individuais dos países reflitam um determinado padrão. Terceiro, segundo Harrison (1996), para teorias do desenvolvimento econômico, as análises por cross-section ou séries temporais individuais não permitem o controle de fatores individuais específicos a cada país que podem enviesar as estimativas calculadas. Por fim, o mesmo autor destaca que as séries temporais individuais são sensíveis às condições iniciais de cada economia, principalmente no que diz respeito ao período anterior ou posterior ao país ter adotado alguma política para o crescimento. Assim, análises de painel, que incluem sucessivas séries de diferentes economias, permitem a amenização desse problema.

Na segunda parte do trabalho, será discutido o papel da política comercial nos modelos de desenvolvimento latino-americanos, desde o modelo de Industrialização por Substituição de Importações, até o Consenso de Washington. Também serão abordados outros estudos empíricos sobre a possibilidade de restrições externas ao crescimento econômico na região.

Na terceira parte do trabalho, será desenvolvido o modelo de Thirlwall. Na quarta parte, será apresentado um resumo sobre as técnicas de dados em painel utilizadas para estudo empírico, assim como os dados 
e as variáveis de suas estimativas. Os resultados serão abordados na quinta parte do estudo, que procurará investigar as variáveis econômicas latino-americanas e caribenhas comparando as técnicas de painel utilizadas e testando a robustez dos resultados estimados.

\section{Inserção Internacional das Economias Latino-Americanas em uma Perspectiva Histórica: da Substituição de Importações à Liberalização do Comércio}

Da década de 1930 até o final da década de 1970, a regra geral das políticas comerciais das economias latino-americanas foi, na maioria dos casos, pautada pelo protecionismo aduaneiro. As autoridades econômicas dos países, com o objetivo de proteger suas indústrias nascentes, costumavam levantar diversos arranjos de restrições comerciais e cambiais à importação de bens industrializados de consumo, tais como a introdução de taxas de câmbio múltiplas, tarifas protecionistas para importação de bens com similares produzidos nacionalmente, e a imposição de licenças e de quotas para importações. ${ }^{1}$

A base teórica que dava sustentação a essas políticas protecionistas e ao modelo de desenvolvimento por substituição de importações em geral foi o pensamento econômico da Comisión Económica para América Latina y el Caribe (CEPAL), principalmente pelas ideias do economista argentino Raúl Prebisch (1901-1986). De acordo com sua teoria do comércio internacional, denominada de hipótese Prebisch-Singer, há uma tendência estrutural para a deterioração dos termos de intercâmbio (razão entre os preços dos bens exportados e dos bens importados) dos países exportadores de bens primários, por três mecanismos. Primeiro, porque a elasticidade-renda e a elasticidade-preço dos bens primários são menores do que as de bens industrializados, fazendo com que o crescimento econômico dos países subdesenvolvidos de economia agroexportadora acabe sendo sempre restringido por déficits na balança de pagamentos, uma vez que as importações tendem a crescer em ritmo superior do que exportações (PREBISCH, 1982c). Segundo, a produção de bens industrializados está mais relacionada ao progresso tecnológico do que a produção de bens primários, proporcionando ganhos contínuos de produtividade aos países desenvolvidos (PREBISCH, 1982a). Terceiro,

1 Detalhes mais técnicos sobre o papel das políticas cambiais e aduaneiras sobre o protecionismo nas economias latino-americanas durante esse período estão presentes no estudo de Cardoso e Helwege (1993). 
os países industrializados apresentam mercados de bens menos competitivos e mercado de trabalho mais rígido, de modo que os ganhos do progresso técnico acabam sendo melhor apropriados pelos seus fatores de produção e os preços de sua produção são menos sensíveis às oscilações econômicas internacionais. Em economias agroexportadoras, por outro lado, isso não acontece, de modo que os ganhos do progresso tecnológico acabam sendo apropriados pelos consumidores estrangeiros (PREBSICH, 1949). ${ }^{2}$

É inegável que o modelo de Industrialização por Substituição de Importações (ISI) proporcionou uma considerável contribuição para o desenvolvimento das economias latino-americanas. Contudo, o modelo de ISI acabou entrando em constantes crises, e, posteriormente, em colapso após os choques do petróleo na década de 1970, devido a seus próprios problemas internos. Em primeiro lugar, por causa da insustentabilidade dos constantes desequilíbrios comerciais, já que as exportações eram penalizadas pelas políticas cambiais de apoio à sobrevalorização real. ${ }^{3}$ Em segundo lugar, pela distorção exercida pelos mecanismos de proteção na relação entre preços internos e internacionais, o que criou incentivos a uma menor eficiência da produção doméstica em relação à estrangeira. Desse modo, as indústrias da região acabaram nunca se tornando internacionalmente competitivas ao longo do período em que vigorou a ISI. Por fim, a já referida tendência estrutural a desequilíbrios externos criou uma situação de constante escassez de divisas geradas na região, fazendo com que as economias dependessem cada vez mais de endividamento estrangeiro para financiar seus investimentos. ${ }^{4}$

Todos esses problemas, que acarretaram o fim da ISI, fizeram com que a década de 1980 fosse denominada uma "década perdida", isto é,

2 Além da hipótese Prebisch-Singer, Cardoso e Helwege (1993) destacam outros fatores, de ordem econômica ou política, que justificaram a implementação do modelo de substituição de importações nas economias latino-americanas.

3 As taxas de câmbio reais valorizadas traziam o benefício de baratear os custos das indústrias nacionais dependentes de insumos importados.

4 A bibliografia também indica diversos outros fatores como contribuintes para a crise do modelo de ISI na América Latina. Por exemplo, Coutinho (1996) destaca que a tendência ao déficit orçamentário por parte dos governos latino-americanos, por causa de seus impactos negativos sobre a estabilidade monetária e o endividamento externo de suas economias, limitou o ânimo dos empresários estrangeiros a realizar investimentos diretos em setores de maior risco nas economias latino-americanas. Além disso, são fatores igualmente relevantes a crise do endividamento externo estourada pela elevação dos juros internacionais após o segundo choque do petróleo, em 1979 (BENECKE; NASCIMENTO, 2003); a defasagem tecnológica da produção doméstica protegida, e seus impactos regressivos sobre a distribuição de renda (BAER, 2002); a mobilidade crescente de fluxos financeiros em nível internacional, que constrangeu a realização de políticas econômicas expansionistas (FRANCO, 1999); e a deterioração institucional dos mecanismos de planejamento econômico adotados pelos países, que eram essenciais ao modelo de ISI (BAER, 2002). 
de recessão, em um processo de transição entre modelos de desenvolvimento econômico na América Latina. Nesse período, as políticas econômicas da região voltaram-se para a correção de seus desequilíbrios macroeconômicos, como a estabilização de preços e para a realização de reformas estruturais, de modo a estimular a inserção internacional de suas produções e de reduzir o papel do Estado na economia. A preocupação com o crescimento econômico acabou posta de lado.

Baer (2002) aponta para dois motivos fundamentais para a liberalização comercial e econômica dos países latino-americanos após a crise do modelo de ISI. Primeiro, a necessidade das economias da região de auferir ganhos quantitativos e qualitativos em relação às suas exportações, de modo a corrigir o até então estrutural desequilíbrio externo. Segundo, a pressão externa por parte dos credores das suas dívidas, que procuravam sinalizações de bons fundamentos macroeconômicos (como a redução do déficit público e da inflação) para continuar investindo nessas economias.

As novas diretrizes de política econômica, de acordo com o novo modelo, foram sintetizadas por um artigo de John Williamson, escrito em 1989, que ficou internacionalmente conhecido pelo nome de "Consenso de Washington". Esse trabalho consiste em um resumo das proposições feitas pelas principais instituições econômicas mundiais para orientar as reformas estruturais nas economias americanas, com o objetivo de recuperar o seu crescimento após a crise nos anos oitenta. Das dez políticas listadas no Consenso de Washington (WILLIAMSON, 2004), duas são diretamente relacionas à política comercial: a introdução de sistemas cambiais unificados e competitivos em cada país e a liberalização do comércio internacional.

Em primeiro lugar, como um sistema cambial unificado e competitivo, o autor sugere que o comércio internacional deve ser um dos motores do crescimento econômico latino-americano no novo modelo, e a política cambial deve ser utilizada para estimular as exportações. Contudo, o autor afirma que os modelos cambiais adotados pelos países da região devem ser unificados, isto é, de taxas únicas, fixas ou flutuantes, mas não de variações mais criativas, como as taxas múltiplas, para evitar distorções nos sistemas de preços.

Já no que diz respeito à liberalização comercial, o autor defende a eliminação de barreiras quantitativas ao comércio, a substituição de barreiras não-tarifárias por tarifas de importação e a redução progressiva destas mesmas. Williamson (2004) aponta para dois motivos pelos quais a proteção por tarifas de importação é menos nociva à eficiência econômica do que por barreiras não-tarifárias. Primeiro, porque as tarifas rendem receitas monetárias para o governo, e não para determinados 
agentes importadores privilegiados. Segundo, porque a eliminação de barreiras quantitativas à importação permite que a variação do volume de bens importados responda a choques macroeconômicos que elevem a demanda doméstica, diminuindo assim o seu efeito contra a estabilidade nominal. Para o autor, a liberalização comercial não elevaria o desemprego estrutural nas economias latino-americanas porque o próprio protecionismo já consiste em um sistema mais nocivo à criação de empregos, devido à ineficiência econômica que acarreta. Além disso, qualquer potencial desequilíbrio externo poderia ser corrigido por uma política cambial adequada.

A partir do final da década de 1980, praticamente todos os países latino-americanos adotaram medidas e reformas econômicas de acordo com os preceitos do Consenso de Washington. Contudo, mesmo apresentando taxas de crescimento superiores às da "década perdida", as economias latino-americanas mantiveram uma trajetória de crescimento inferior ao obtido no auge do modelo de ISI, e também inferior a dos demais países em desenvolvimento, tais como os asiáticos. Além disso, o ritmo do desenvolvimento econômico foi muito desigual entre os países, sendo, por exemplo, mais pronunciado no Chile e no México do que na Argentina e na Bolívia. Tais fatos acarretaram, por parte de diversos autores, em muitas críticas ao Consenso de Washington original.

Uma das principais fontes de críticas, que é exatamente o ponto principal do presente trabalho, refere-se à possibilidade das economias latino-americanas, operando em um arranjo de livre comércio internacional, não conseguirem competir com a produção estrangeira. Nesse caso, há a possibilidade das economias voltarem a se tornar exportadoras de bens primários, com o risco de até mesmo se "desindustrializar". Remetendo à teoria de Raúl Prebisch e adotando as preposições formalizadas por McCombie e Thirwall (1994), como a demanda por bens de tecnologia mais simples, tais quais os bens primários, é menos elástica em relação a preços e renda do que a demanda por bens industrializados, poderia haver o risco da demanda interna dos países latino-americanos por importações ter uma tendência de crescer em ritmo superior ao da demanda internacional por suas exportações. Isso provocaria um desequilíbrio externo estrutural, capaz de comprometer o seu crescimento econômico.

Nesse sentido, novos estudos empíricos que procuraram estimar as elasticidades do comércio internacional e a sua relação com o crescimento econômico latino-americano já foram realizados por diversos autores. Os primeiros trabalhos nessa direção utilizaram técnicas de séries temporais individuais para analisar o caso de um único país, ou de grupos de países em abordagem comparativa. Os procedimentos 
econométricos utilizados nesses trabalhos baseavam-se, fundamentalmente, em testes de raízes unitárias do tipo Augmented Dickey-Fuller (ADV), seguido pela estimação por vetores autorregressivos (VAR) e por análises de cointegração, como o teste de Johansen.

Um dos primeiros trabalhos desse tipo elaborado para a América Latina foi o estudo de López e Cruz (2000). Os autores abordaram as economias da Argentina, Brasil, Colômbia e México de 1965 a 1996, e utilizaram procedimentos econométricos de séries temporais individuais com variáveis de diferentes ordens de integração. Foi concluído que a balança comercial de todos os países, tal como esperado, apresenta uma relação positiva com o crescimento econômico externo, que acelera as exportações, e negativa com o crescimento econômico interno, que acelera as importações. Além disso, os autores encontraram uma relação estável entre a taxa real de câmbio e o produto, de sinal positivo para a Colômbia e o México, e negativo para o Brasil e a Argentina. ${ }^{5}$ Essa relação, segundo os autores, seria um indicativo de que a política cambial tem papel importante para o crescimento econômico de longo prazo, ao contrário do que outras abordagens pressupõem, e que sucessivas desvalorizações cambiais podem reprimir a demanda interna, como parece ser o caso do Brasil e da Argentina, por prejudicar a importação de bens de capital pelas empresas, provocar incerteza sobre o clima dos negócios e por acelerar a inflação, reduzindo o consumo privado.

Moreno-Brid e Pérez (2003), em um estudo semelhante ao anterior, procuraram examinar a relação de longo prazo entre a performance das exportações e o crescimento econômico da Costa Rica, El Salvador e Guatemala no período de 1950 a 1999. Os autores elaboraram uma análise dinâmica da evolução das elasticidades-renda das exportações e importações nos países da amostra. Nessa análise, as séries temporais foram quebradas em períodos de trinta anos, de 1950-1980 e 1969-1999, com o objetivo de observar a variação dessas elasticidades antes e depois de 1986, ano no qual foram implementadas políticas de liberalização comercial nos três países. Foi concluído que, em geral, a elasiticidaderenda das importações é mais estável do que a das exportações nos três países. Além disso, El Salvador e Guatemala apresentaram um crescimento da elasticidade das importações superior ao da elasticidade das exportações após 1986, o que certamente contribuiu para os seus baixos níveis de crescimento após esse ano. A Costa Rica, por outro lado,

5 Uma crítica a essa conclusão foi elaborada no trabalho de Holland, Vieira e Canuto (2004). Segundo esses autores, a relação entre a taxa de câmbio real e o produto não pode ser vista como sendo direta. Ela depende da relação do câmbio com o comércio exterior, que, por sua vez, depende das elasticidades da demanda interna e externa em relação às respectivas rendas. 
como conseguiu mudar sua estrutura exportadora, incorporando na sua pauta bens de tecnologia mais elevada ao longo do período pós-1986, conseguiu superar a restrição externa ao crescimento econômico.

Uma abordagem para o caso brasileiro foi feita por Jayme Jr. (2003). O autor abordou o período de 1955 a 1998, procurando estudar, de maneira comparativa, a relação entre o comércio exterior e o crescimento econômico, tanto no período de ISI como nas décadas posteriores. A elasticidade das importações não foi afetada significantemente com a liberalização comercial adotada em 1990, mas sim com o colapso do modelo de ISI ocorrido em 1980. Em uma análise dinâmica semelhante à realizada no estudo de Moreno-Brid e Pérez (2003), o autor verificou que, a partir dos anos 70, o Brasil cresceu menos do que o compatível com equilíbrio na balança comercial, e apontou como hipóteses para esse fato o papel dos fluxos de capital externo e da dinâmica da liquidez do mercado financeiro internacional. Por fim, a partir de uma estimação baseada em um vetor de correção de erros (VEC), o autor verificou uma relação simultânea de curto prazo entre o nível de produto e de exportações, o que dificulta o estabelecimento de uma relação causal entre esses dois fatores.

Resultados semelhantes foram obtidos por Pacheco-López (2005) para a economia mexicana no período de 1970 a 2000. A autora verificou que a liberalização do comércio provocou um crescimento das importações acima das exportações em todo o período após a liberalização comercial. Além disso, tal como no estudo de Jayme Jr. (2003), a autora também verificou que o crescimento observado do produto mexicano tende a ser inferior ao nível compatível com equilíbrio na balança de pagamentos.

Estudos com amostras maiores de países latino-americanos foram elaborados por Holland, Vieira e Canuto (2004) e Lizardi (2006). O primeiro deles utilizou uma amostra de 10 países no período de 1950 a 2000, e chegou ao resultado de que o parâmetro estimado para as elasticidades-renda das importações tende a ser menor nos países com maior crescimento. Lizardi (2006), por sua vez, abordou 19 economias da região de 1900 a 2000. O estudo corroborou a relação expressiva entre o crescimento econômico dos países latino-americanos e dos Estados Unidos, que é o seu principal mercado importador. Além disso, o autor destacou uma tendência de crescimento da razão entre a elasticidade das importações e das exportações em todos os países da amostra, com a exceção do Chile. Por fim, ambos os estudos verificaram que o crescimento econômico real dos países tende a ser superior ao compatível com o nível de equilíbrio na balança de pagamentos. Esse resultado contrasta com os dos estudos abordados anteriormente, mas pode 
refletir o fato de que os autores, aqui, trabalharam com séries temporais maiores, de modo que os dados utilizados para mensurar o crescimento econômico real cobrem os períodos de maior crescimento dos países latino-americanos - isto é, durante o modelo de ISI.

Alguns dos principais estudos agregativos sobre a relação entre o comércio internacional e o crescimento econômico na América Latina são os trabalhos de Pacheco-López e Thirlwall (2006), Pacheco-López (2009) e de Cimoli, Porcile e Rovira (2010). Pacheco-López e Thirlwall (2006), utilizando uma amostra de 17 países para o período de 1977 a 2002, estimaram essa relação tanto para a região como um todo, utilizando o método dos mínimos quadrados empilhados, como para cada país isoladamente, utilizando séries temporais. Os autores calcularam que a elasticidade-renda das importações para o agregado da região é compatível com um crescimento do produto de $2,4 \%$ ao ano. Para países individuais, o estudo corroborou os resultados de Moreno-Brid e Pérez (2003), ou seja, foi verificado que o efeito da taxa de câmbio real sobre o comércio é pouco significante, ao contrário das elasticidades-renda, que são parâmetros importantes para a grande maioria dos países da amostra. ${ }^{6}$ Por isso, as restrições externas são destacadas como fatores capazes de explicar o baixo crescimento econômico da maior parte dos países da região a partir de meados da década de oitenta. Por fim, os autores observaram que os países que apresentaram maior crescimento da elasticidade das importações ao longo do período foram as maiores economias da região, como o Brasil, a Argentina e o México.

Pacheco-López (2009), utilizando a mesma base de dados do seu trabalho anterior, além de corroborar as conclusões tomadas anteriormente, verificou que a liberalização comercial deteriorou a situação de trade-off entre crescimento econômico e saldo da balança comercial em toda a região. Esse resultado foi obtido utilizando-se diferentes procedimentos econométricos, tais como a estimação por séries temporais individuais, por mínimos quadrados empilhados e por técnicas de dados em painel. Após a liberalização comercial, a maior parte dos países da região obteve melhores saldos em balança comercial ou uma aceleração do crescimento econômico, mas apenas o Chile e a Venezuela obtiveram os dois resultados simultaneamente. Segundo a autora, isso reflete fatores particulares a cada caso, tal como a maior gradualidade das reformas liberalizantes no Chile e o papel do petróleo sobre o setor exportador venezuelano.

Uma análise comparativa da evolução das elasticidades do comércio internacional de uma amostra de oito economias latino-americanas

As exceções são a República Dominicana e a Nicarágua. 
de 1960 a 2004 em relação a amostras de países desenvolvidos e asiáticos foi feita por Cimoli, Porcile e Rovira (2010). Os autores, em uma abordagem dinâmica utilizando o método de dados em painel com efeitos fixos, chegaram ao resultado de que a elasticidade-renda das importações dos países latino-americanos teve picos nos anos setenta e noventa, e uma ligeira redução nos anos oitenta, ao passo que, nos países desenvolvidos, essa relação foi estável, e nos países asiáticos o seu crescimento foi acompanhado e até mesmo superado em certos períodos por um crescimento simultâneo das exportações. Esses resultados explicam o melhor desempenho macroeconômico dos países asiáticos sobre os latino-americanos nas últimas décadas. Os períodos em que a elasticidade das importações foi mais elevada na América Latina, segundo os autores, coincidem com as épocas em que os governos na região praticaram políticas de liberalização comercial e sobrevalorização cambial, sendo que esse último fator, por sua vez, é consequência de políticas macroeconômicas restritivas. Por fim, os autores destacam que quebras estruturais de redução dessa elasticidade de importações em países subdesenvolvidos são invariavelmente associadas a transformações na estrutura econômica e exportadora desses países, favorecendo os setores com maior eficiência tecnológica, tal como verificado no estudo de Moreno-Brid e Pérez (2003).

Um resumo das estimativas das elasticidades-renda da demanda por importações relativas a países latino-americanos, feitas pelos estudos empíricos aqui referidos, encontra-se no Quadro 1.

\begin{tabular}{|c|c|c|c|}
\hline Estudo & Série Anual & Países abordados & Estimativa \\
\hline López e Cruz (2000) & $1965-1996$ & Argentina & 2,8 \\
\hline & & Brasil & 1,03 \\
\hline & & Colômbia & 1,8 \\
\hline $\begin{array}{c}\text { Moreno-Brid } \\
\text { e Pérez (2003) }\end{array}$ & $1950-1999$ & México & 1,3 \\
\hline & & Costa Rica & 1,36 \\
\hline & & El Salvador & 1,49 \\
\hline Jayme Jr. (2003) & $1955-1998$ & Guatemala & 1,2 \\
\hline & $1966-1980$ & Brasil & 2,38 \\
\hline & $1981-1998$ & Brasil & 2,21 \\
\hline Holland et al. (2004) & $1950-2000$ & Brasil & 2,58 \\
\hline & & Brasil & 2,59 \\
\hline $\begin{array}{c}\text { Pacheco-López } \\
\text { (2005) }\end{array}$ & $1974-1989$ & México & 4,58 \\
\hline
\end{tabular}

(continua) 


\begin{tabular}{|c|c|c|c|}
\hline & $1984-1999$ & México & 3,14 \\
\hline $\begin{array}{c}\text { Pacheco-López e } \\
\text { Thirlwall (2006) }\end{array}$ & $1977-2002$ & Painel de 17 países & 2,29 \\
\hline & $1977-1990$ & Painel de 17 países & 2,04 \\
\hline & $1989-2002$ & Painel de 17 países & 2,82 \\
\hline $\begin{array}{c}\text { Cimoli, Porcile e } \\
\text { Rovira (2010) }\end{array}$ & $1961-2004$ & Painel de 8 países & 2,13 \\
\hline & $1961-1970$ & Painel de 8 países & 1,85 \\
\hline & $1971-1980$ & Painel de 8 países & 3,17 \\
\hline & $1981-1990$ & Painel de 8 países & 1,58 \\
\hline & $1991-2004$ & Painel de 8 países & 2,97 \\
\hline
\end{tabular}

Quadro 1 - Estimativas para a Elasticidade-Renda das Importações Latino-Americanas Calculadas em Estudos Empíricos Anteriores

Fonte: Elaborado pelo autor a partir dos estudos referidos.

É importante destacar que houve um estudo empírico anterior aos até agora citados, elaborado por Harrison (1996), que procurou estimar a relação entre o crescimento econômico e a abertura comercial em países subdesenvolvidos, mensurada por diversos indicadores. Utilizando um modelo de dados em painel com efeitos fixos, o autor chegou à conclusão de que a relação entre os dois fatores é positiva e estatisticamente robusta. No entanto, cabe fazer duas ressalvas a esse estudo. Em primeiro lugar, foi utilizada uma amostra com países de diferentes continentes, com arcabouços institucionais e contextos históricos totalmente distintos. Em segundo lugar, o autor admite que, em muitos casos, a relação de causalidade entre as duas variáveis pode ser reversa, no sentido de que os países com maior crescimento são mais propensos a abrir seus mercados para as importações. No entanto, esse não é o caso da América Latina, em que a liberalização comercial foi realizada em um contexto de crise generalizada e duradoura.

\section{Crescimento Econômico e Restrições na Balança de Pagamentos: o Modelo de Thirlwall}

Segundo a teoria macroeconômica pós-keynesiana, que não pressupõe equilíbrio com pleno-emprego, o crescimento econômico é impulsionado pelos fatores relacionados ao lado da demanda agregada, em relação a qual, dentro de certos limites, a oferta se ajusta. Nas economias abertas, o principal componente autônomo da demanda 
agregada são as exportações, e, por isso, esse fator é considerado por muitos autores como o principal componente dinâmico das economias. ${ }^{7}$

Segundo Harrod (1933), um país enfrentará desequilíbrios comerciais ao longo de seu crescimento do produto se a elasticidade-renda da sua demanda por importações for superior à elasticidade-renda da demanda externa por suas exportações. Em outras palavras, as restrições na balança de pagamentos ocorrem em uma economia quando a sua demanda interna por importações tende a crescer estruturalmente em um ritmo superior à demanda internacional por exportações. Tal problema acaba por constituir um obstáculo para o crescimento econômico, já que, nesses casos, a política econômica - fiscal e monetária - acaba sendo utilizada para controlar esses desequilíbrios comerciais, restringindo a demanda doméstica, provocando recessão, com impacto negativo e duradouro sobre os níveis de emprego e de investimentos. McCombie e Thirlwall (1994) descrevem a existência de um círculo vicioso na economia, caso a mesma seja constantemente afetada por desequilíbrios na balança de pagamentos:

If a country gets into balance-of-payments difficulties as it expands demand before the short-term capacity growth rate is reached, then demand must be curtailed; supply is never fully utilized; investment is discouraged; technological progress is slowed down, and a country's goods compared with foreign goods become less desirable so worsening the balance of payments still further, and so on. A vicious circle is started. By contrast, if a country is able to expand demand up to the level of existing productive capacity, without balance-ofpayments difficulties arising, the pressure of demand upon capacity may well raise the capacity growth rate (MCCOMBIE; THIRLWALL, 1994, p. 233).

Formalizando o modelo de Thirlwall, ${ }^{8}$ uma balança de pagamentos em equilíbrio apresenta a seguinte igualdade:

$$
P_{d} X=P_{f} M E
$$

Em que $\mathrm{X}$ representa o volume de exportações, $\mathrm{Pd}$ equivale ao preço das exportações em moeda doméstica, $M$ é o volume de impor-

$7 \quad$ De acordo com Thirlwall e McCombie (1994, p. 233), "It this argument that lies behind the advocacy of export-led growth, because it is only through the expansion of exports that the growth rate can be raises without the balance of payments deteriorating at same time." Isso porque, como afirma a teoria macroeconômica, o crescimento da absorção interna tende a elevar a demanda por importações.

8 A derivação do modelo segue a versão original em Thirlwall e McCombie (2004), com alguns detalhes de elaboração própria. 
tações, Pf é o preço das importações em moeda estrangeira, e E mensura a taxa de câmbio.

Em termos dinâmicos, supõe-se que um ritmo de crescimento com equilíbrio na balança de pagamentos exige que a variação do valor das exportações seja capaz de acompanhar a variação no valor das importações. Passando (1) para logaritmos, tem-se:

$$
p_{d}+x=p_{f}+m+e
$$

A demanda interna por importações, assim como a demanda externa por exportações, depende dos preços relativos dos produtos domésticos e dos produtos estrangeiros, e da renda doméstica $(Y)$ e estrangeira (Z):

$$
\begin{aligned}
& M=a\left(P_{f} E / P_{d}\right)^{\psi} Y^{\pi} \\
& X=b\left(P_{d} / P_{f} E\right)^{\eta} Z^{\varepsilon}
\end{aligned}
$$

Nessas equações, "a" e "b" são constantes, $\psi$ é a elasticidade-preço das importações, e $\pi$ é a elasticidade-renda da demanda por importações, $\eta$ é a elasticidade-preço das exportações, e $\varepsilon$ é a elasticidade-renda da demanda internacional pelas exportações domésticas. ${ }^{9}$ Passando para logaritmos:

$$
\begin{gathered}
\mathrm{m}=\psi\left(\mathrm{p}_{\mathrm{f}}+\mathrm{e}-\mathrm{p}_{\mathrm{d}}\right)+\pi \mathrm{y} \\
\mathrm{x}=\eta\left(\mathrm{p}_{\mathrm{d}}-\mathrm{p}_{\mathrm{f}}-\mathrm{e}\right)+\varepsilon \mathrm{z}
\end{gathered}
$$

Substituindo (5) e (6) em (2) e resolvendo para y, pode-se encontrar a taxa de crescimento econômico compatível com um equilíbrio na balança de pagamentos, $\mathrm{y}_{\mathrm{BP}}$ :

$$
\mathrm{y}_{\mathrm{BP}}=\left[(1+\eta+\psi)\left(\mathrm{p}_{\mathrm{d}}-\mathrm{p}_{\mathrm{f}}-\mathrm{e}\right)+\varepsilon z\right] / \pi
$$

Por simplificação, pode-se assumir que os preços relativos dos bens domésticos e estrangeiros são constantes no longo prazo, de modo que

9 Observa-se que os sinais dos parâmetros das elasticidades presentes no modelo seguem os pressupostos básicos de uma curva de demanda tradicional. As elasticidades-preço das exportações e importações são negativas, e as elasticidades-renda da demanda por bens exportados e importados são positivas. Então, $\eta<0, \psi<0, \varepsilon<0$ e $\pi<0$. 
há uma convergência nas taxas de inflação nacional e internacional $\left(\mathrm{p}_{\mathrm{d}}-\mathrm{p}_{\mathrm{f}}=0\right)$. Pode-se assumir também que as desvalorizações cambiais não são permanentes $(\mathrm{e}=0)$. Assim, tem-se que:

$$
\mathrm{y}_{\mathrm{BP}}=\varepsilon \mathrm{Z} / \pi=\mathrm{x} / \pi
$$

A equação (8) é denominada de Lei de Thirlwall, e afirma que a taxa de crescimento em equilíbrio da balança de pagamentos de cada economia é uma função direta da elasticidade-renda da demanda externa por suas exportações e da renda internacional, isto é, do valor total exportado, e uma função inversa da elasticidade-renda da sua demanda por importações.

O modelo adotado para a estimação empírica da lei de Thirwall na América Latina foi desenvolvido por Moreno-Brid e Pérez (2003), em seu estudo sobre os países da América Central. Esse modelo representa as equações (5) e (6) como, respectivamente:

$$
\begin{aligned}
& \ln \left(\mathrm{m}_{\mathrm{t}}\right)=\mathrm{a}_{0}+\pi \ln \left(\mathrm{y}_{\mathrm{t}}\right)+\psi \ln \left(\mathrm{Pm}_{\mathrm{t}} / \mathrm{Pd}_{\mathrm{t}}\right)+\mathrm{u}_{\mathrm{t}} \\
& \ln \left(\mathrm{x}_{\mathrm{t}}\right)=\mathrm{b}_{0}+\varepsilon \ln \left(\mathrm{z}_{\mathrm{t}}\right)+\eta \ln \left(\mathrm{Px}_{\mathrm{t}} / \mathrm{P}_{\mathrm{t}}^{*}\right)+\mathrm{u}_{\mathrm{t}}
\end{aligned}
$$

Como proxy para os termos de intercâmbio (os termos $\mathrm{Pm}_{\mathrm{t}} / \mathrm{Pd}_{\mathrm{t}} \mathrm{e}$ $\left.\mathrm{Px}_{\mathrm{t}} / \mathrm{P}^{*}\right)$, os autores recomendam o uso da taxa de câmbio real (EP*/P), em que E é o câmbio nominal, $\mathrm{P}^{*}$ é o nível internacional de preços, e P são os preços internos. Para simplificar a estimação, como proxy para $\mathrm{P}^{*}$ foi utilizado o nível de preços nos Estados Unidos. Já a renda externa, $\mathrm{Zt}$, foi mensurada como o somatório do PIB a preços constantes de 2000 dos principais parceiros comerciais externos da América Latina. ${ }^{10}$

\section{Metodologia e Dados}

A metodologia adotada no presente trabalho é a estimação por dados em painel, que consiste na combinação de observações cross-section e de séries temporais. Assim, acompanha-se o comportamento das variáveis relacionadas aos mesmos indivíduos observados (no caso, os países da América Latina) ao longo de um determinado período de tempo. ${ }^{11}$

O uso de métodos de estimação por painel trás uma série de vantagens em relação à estimação de cross-sections agrupadas para todos

10 Estados Unidos, Reino Unido, França, Alemanha, Espanha, Japão e China.

11 Mais detalhes sobre as técnicas de estimação aqui descritas encontram-se em Wooldridge (2006a; 2006b). 
os países selecionados na amostra - como é mais comum nos estudos empíricos envolvendo o modelo de Thirlwall. Em primeiro lugar, permite o controle de heterogeneidades entre os países observados, isto é, variáveis específicas a cada caso que poderiam enviesar os resultados da estimação por cross-section ou por séries temporais. Esse problema é muito importante para estudos macroeconômicos, os quais precisam levar em conta as peculiaridades econômicas específicas entre países estruturalmente muito distintos. Em segundo lugar, o uso de painel para estimações empíricas macroeconômicas permite a inclusão de uma maior variabilidade nos dados coletados, por acrescentar observações de cross-section às tradicionais séries temporais individuais.

O presente estudo adota dois modelos distintos de estimação por dados em painel: o modelo de primeiras diferenças e o modelo de efeitos fixos. Basicamente, ambos os modelos partem do pressuposto de que quaisquer efeitos fixos no tempo relacionados às observações individuais em cross-section são correlacionados com os regressores. Por isso, a estimação de um modelo diretamente por mínimos quadrados ordinários empilhados (MQOE) poderia levar a um viés de heterogeneidade, provocado pela não-inclusão de uma variável relevante do modelo por ser constante no tempo, mas que afeta parte da sensibilidade dos regressores em relação à variável dependente.

O procedimento de primeira diferenciação elimina o efeito-fixo do modelo pela subtração da equação estrutural do modelo em cada período de tempo pela sua primeira defasagem. Contudo, esse modelo exige que a variação dos regressores seja não-correlacionada com a variação dos resíduos, o que elimina os casos em que a série temporal é autorregressiva. Além disso, é necessário que os regressores tenham variabilidade ao longo do tempo e que os erros sejam homoscedásticos. Se os erros forem heteroscedásticos, deve-se corrigí-los pelo uso de estimadores de mínimos quadrados generalizados factíveis.

O procedimento de efeitos-fixos, por sua vez, subtrai cada equação estrutural de sua média ao longo do tempo. Porém, esse método exige que os erros sejam não-correlacionados com os regressores em todos os períodos de tempo (hipótese de exogeneidade estrita). Além disso, supõe-se que os erros sejam homoscedásticos e que não apresentem correlação serial. Caso essa hipótese seja satisfeita, a estimação por efeitos fixos é eficiente para dados em painel. Contudo, principalmente em modelos com muitos períodos de tempo e poucos indivíduos observados, essa hipótese pode ser forte demais.

A amostra compreende 30 países da América Latina e Caribe, incluindo todos os países sul-americanos e centro-americanos indepen- 
dentes, e todos os Estados soberanos do Caribe (com a exceção de Cuba e Barbados).

Os dados anuais utilizados na presente estimação foram coletados em três bases distintas: o Anuário Estatístico da América Latina e do Caribe (2006), da CEPAL; o World Economic Outlook Database for October 2007, do FMI; e o Statistical Databases, da ONU. O período de análise vai de 1980 a 2005.

As variáveis incluídas no trabalho estão descritas nos Quadros 2 e 3.

\begin{tabular}{|c|c|c|}
\hline Variável & Descrição & Observações \\
\hline $\ln \_$exp & $\begin{array}{c}\text { Logaritmo do valor total } \\
\text { das exportações de bens e de } \\
\text { serviços de cada país, em dólares. }\end{array}$ & $\begin{array}{c}\text { Fonte: Comisión Económica para } \\
\text { América Latina y el Caribe (2006). }\end{array}$ \\
\hline $\ln \_i m p$ & $\begin{array}{c}\text { Logaritmo do valor total } \\
\text { das importações de bens e de } \\
\text { serviços de cada país, em dólares. }\end{array}$ & $\begin{array}{c}\text { Fonte: Comisión Económica para } \\
\text { América Latina y el Caribe (2006). }\end{array}$ \\
\hline
\end{tabular}

Quadro 2 - Variáveis Dependentes.

Fonte: Elaborado pelo autor.

\begin{tabular}{|c|c|c|}
\hline Variável & Descrição & Observações \\
\hline ln_pib & $\begin{array}{l}\text { Logaritmo do produto interno bruto } \\
\text { de cada país, a preços constantes } \\
\text { (dólares de 2000). }\end{array}$ & Fonte: United Nations (2007). \\
\hline ln_pib_ext & $\begin{array}{l}\text { Logaritmo do produto interno bruto } \\
\text { dos principais parceiros comerciais } \\
\text { da América Latina, a preços } \\
\text { constantes (dólares de 2000). }\end{array}$ & $\begin{array}{c}\text { Somatório do PIB de EUA, Japão, } \\
\text { Alemanha, China, Reino Unido, } \\
\text { França e Espanha. Fonte: United } \\
\text { Nations (2007). }\end{array}$ \\
\hline nivel_precos & $\begin{array}{l}\text { Índice de nível de preços ao consu- } \\
\text { midor, para cada país }(2000=100) \text {. }\end{array}$ & $\begin{array}{c}\text { Fonte: International Monetary } \\
\text { Found (2007) }\end{array}$ \\
\hline precos_eua & Nível de preços nos Estados Unidos. & $\begin{array}{l}\text { Proxy para mensurar o nível interna- } \\
\text { cional de preços. Fonte: Internatio- } \\
\text { nal Monetary Found (2007). }\end{array}$ \\
\hline cambio_n & $\begin{array}{l}\text { Câmbio nominal em moedas nacio- } \\
\text { nais por dólar, média anual. }\end{array}$ & $\begin{array}{l}\text { Fonte: International Monetary } \\
\text { Found (2007). }\end{array}$ \\
\hline ln_cambio_r & Logaritmo do câmbio real. & $\begin{array}{c}\text { Proxy para mensurar os termos de } \\
\text { troca de cada país. Igual ao log } \\
\text { [(preços_eua X cambio_n) / nivel_ } \\
\text { precos] }\end{array}$ \\
\hline
\end{tabular}

Quadro 3 - Variáveis Independentes.

Fonte: Elaborado pelo autor.

Ao longo do período analisado (1980-2005), a economia latinoamericana cresceu a uma taxa média de $2,59 \%$ ao ano. Na década de 80 , essa taxa foi de apenas $1,83 \%$, ao passo que no período a partir de 
1990, subiu para 3,02\%. Dos 30 países da amostra, os que apresentaram maior crescimento médio anual foram Belize (5,24\%) e Chile (4,82\%). Já os que menos cresceram foram o Haiti, que apresentou uma recessão média anual de $0,77 \%$ no período, e a Guiana, com crescimento médio de $0,59 \%$ ao ano.

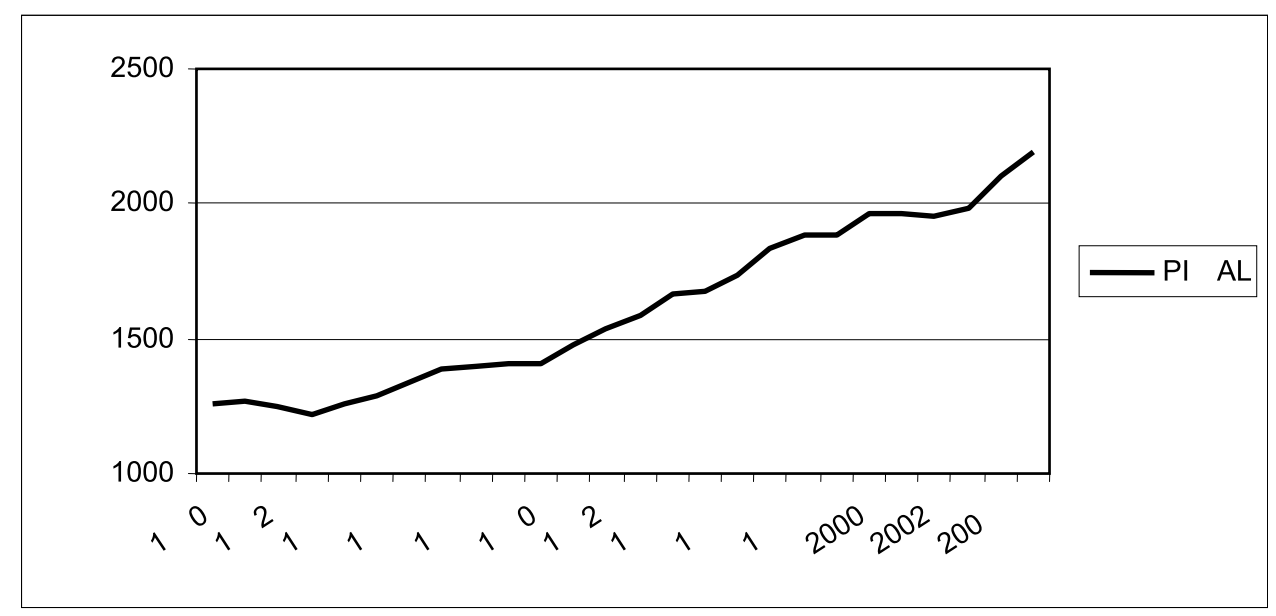

Gráfico 1 - Evolução do PIB agregado na América Latina (1980-2005)

Fonte: United Nations (2007).

O PIB agregado dos principais parceiros comerciais da América Latina cresceu em média $2,94 \%$ ao ano no período, maior na década de 80 (3,31\%), do que no período posterior $(2,74 \%)$. Isso se pode explicar pela desaceleração do crescimento econômico do Japão, da França e da Alemanha a partir da década de 90.

No que diz respeito à evolução do saldo comercial da América Latina no período, pode-se observar quatro períodos distintos. No início da década de 80, houve um déficit provocado pelo choque do petróleo e pelos seus efeitos sobre o valor das importações. Ao longo da década de 80, houve o ajuste, realizado por políticas de contenção de demanda agregada em grande parte dos países da região. Em meados da década de 90, as economias atravessaram novos déficits, financiados por fluxos financeiros externos, graças à estabilização monetária muitas vezes obtida pela valorização cambial. A partir de 1999, com a mudança do padrão cambial brasileiro, essa situação começou a mudar novamente. A partir de 2002, com o ajuste argentino, o saldo voltou a ser de superávit, como mostra o Gráfico 2. 


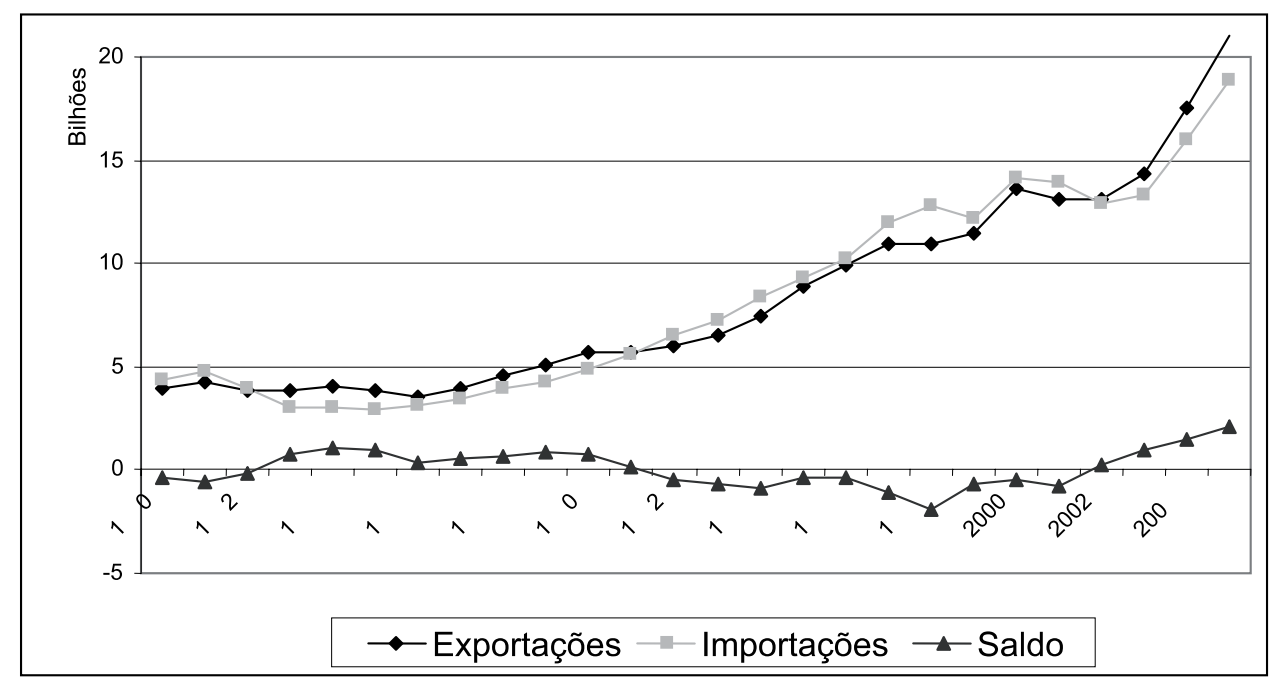

Gráfico 2 - Evolução do Saldo Comercial da América Latina (1980-2005)

Fonte: Comisión Económica para América Latina y el Caribe (2006).

No que diz respeito à taxa de câmbio, destaca-se que uma série de países da amostra utilizou arranjos cambiais fixos ao longo do período estudado. Esses países são: Antígua e Barbuda, Bahamas, Belize, Chile (até 1981), Dominica, República Dominicana (até 1984), Equador (até 1981, e de 2001 a 2005), El Salvador (até 1985, de 1987 a 1989 e de 1995 a 2005), Granada, Guatemala (até 1985), Haiti (até 1990), Honduras (até 1989), Jamaica (até 1982), Panamá, Paraguai (até 1983, e de 1987 a 1988), São Cristóvão e Nevis, Santa Lúcia, São Vicente e Granadinas, Suriname (até 1993, e de 1996 a 1998) e Trindade e Tobago (câmbio fixo ajustável).

\section{Resultados Empíricos}

Conforme sugerido por Pacheco-López e Thirlwall (2006), antes de se efetuar a estimação agregada dos parâmetros, utilizou-se regressões por mínimos quadrados ordinários para cada país individualmente. $\mathrm{O}$ objetivo foi descobrir quais países observados apresentam problemas de estimação específicos, principalmente a não-significância do parâmetro $\pi$, e, se necessário, excluí-los da amostra para as estimações com o uso de técnicas mais refinadas para dados em painel. Devido à presença de autocorrelação serial, as estimativas dos erros-padrão foram realizadas de forma robusta.

Dos países analisados, apenas as Bahamas tiveram seu parâmetro $\pi$ (elasticidade-renda da demanda por importações) não significante a $5 \%$ de significância, e foram excluídas da amostra. Por outro lado, o Haiti apresentou um valor negativo para a elasticidade-renda da demanda 
por importações. Como isso é não-intuitivo em termos econômicos, esse cálculo deve estar afetado por erros de mensuração, por isso o país também foi excluído da amostra.

Um problema observado em muitos dos países da amostra é a não-significância do parâmetro da taxa de câmbio real a 10\%. ${ }^{12}$ MorenoBrid e Pérez (2003), que se depararam com o mesmo problema em seu estudo sobre as economias centro-americanas, apontam para três motivos para esse fato. Em primeiro lugar, devido a pouca variabilidade nos dados sobre o câmbio, sobretudo nas economias com câmbio nominal fixo. Em segundo lugar, pela possível menor sensibilidade do câmbio real ao comércio internacional do que a outros fatores (como aos movimentos de capital em investimentos de portfólio). Por fim, em terceiro lugar, devido ao fato de que, em um horizonte de longo prazo, os fatores nominais têm menos impacto sobre os determinantes de oferta e demanda por importações do que os fatores reais. E ainda, em países de instituições econômicas mais frágeis, é comum a existência de erros de medida. Foram excluídos da amostra os países cujos parâmetros cambiais foram não-significativos a $10 \%$ em ambas as equações, e cuja existência de erros de medida é considerada mais provável: Granada, São Vicente e Granadinas e Suriname. ${ }^{13}$ No agregado, a não significância dos parâmetros cambiais desses países pode levar a viés e heterogeneidade à estimativa por MQOE. Observa-se que, na presença de autocorrelação serial, todos os resultados foram obtidos via estimação robusta, pelo método dos mínimos quadrados generalizados ${ }^{14}(\mathrm{MQG})$.

Já com a amostra ajustada, foram estimadas as equações (9) e (10) por três diferentes métodos: o de mínimos quadrados ordinários empilhados (MQOE), o de primeiras diferenças (PD) e o de efeitos-fixos $(\mathrm{EF})$. Devido à presença de autocorrelação nos resíduos de ambas as equações, foi utilizada a estimação robusta dos erros-padrão para os modelos de MQOE e de PD. Os resultados encontram-se na Tabela 1.

12 Para a equação de demanda por importações, Bolívia, República Dominicana, Granada, Santa Lúcia, São Vicente e Granadinas, Suriname e Trindade e Tobago. Para a equação de exportações, Bolívia, Colômbia, El Salvador, Granada, Honduras, Jamaica, Paraguai, Peru, São Vicente e Granadinas e Suriname.

13 Granada sofreu guerra civil e invasão militar estrangeira na década de 80; o Suriname sofre cronicamente com problemas de contrabando em suas fronteiras; a economia de São Vicente e Granadinas é periodicamente abalada por desastres naturais. Como o tamanho dessas economias é muito pequeno em relação ao resto da região, já que em toda a série temporal o valor do PIB desses três países somados não equivale mais do que $0,01 \%$ do total da região, espera-se que suas exclusões não afetem os resultados das estimações agregadas.

Este método corrige o problema da não-normalidade dos resíduos pela estimação de uma matriz de ponderação. Maiores detalhes podem ser encontrados em Wooldridge (2006a; 2006b). 
Tabela 1 - Resultados das Estimativas da Demanda por Importações

\begin{tabular}{c|c|c|c}
\hline Variável & MQOE & PD & EF \\
\hline Constante & $4.200^{* * *}$ & 0.002 & $-24.571^{* * *}$ \\
& $(0.223)$ & $(0.006)$ & $(0.853)$ \\
\hline ln_pib & $0.761^{* * *}$ & $2.065^{* * *}$ & $2.037^{* * *}$ \\
& $(0.010)$ & $(0.111)$ & $(0.038)$ \\
\hline ln_cambio_r & 0.011 & $-0.140^{* * *}$ & $-0.121^{* * *}$ \\
& $(0.008)$ & $(0.027)$ & $(0.033)$ \\
\hline N. OBS. & 632 & 605 & 632 \\
\hline R2 & 0.915 & 0.407 & -0.985 \\
\hline corr (u_i, Xb) & & & \\
\hline
\end{tabular}

*** Valor significativo a 1\%. ** Valor significativo a 5\%. * Valor significativo a $10 \%$.

Fonte: Elaborada pelo autor.

Tabela 2 - Resultados das Estimativas da Demanda por Exportações

\begin{tabular}{c|c|c|c}
\hline Variável & MQOE & PD & EF \\
\hline Constante & $-56.239^{* * *}$ & $-0.037^{* *}$ & $-49.937^{* * *}$ \\
& $(9.211)$ & $(0.016)$ & $(1.475)$ \\
\hline ln_pib_ext & $2.532^{* * *}$ & $3.508^{* * *}$ & $2.359^{* * *}$ \\
& $(0.303)$ & $(0.497)$ & $(0.050)$ \\
\hline ln_cambio_r & $0.202^{* * *}$ & $-0.092^{* *}$ & $-0.121^{* * *}$ \\
& $(0.022)$ & $(0.025)$ & $(0.037)$ \\
\hline N. OBS. & 632 & 605 & 632 \\
\hline R2 & 0.182 & 0.097 & \\
\hline corr (u_i, Xb) & & & -0.238 \\
\hline
\end{tabular}

*** Valor significativo a 1\%. ** Valor significativo a $5 \% .{ }^{*}$ Valor significativo a $10 \%$.

Fonte: Elaborada pelo autor.

O primeiro modelo estimado foi o de mínimos quadrados ordinários empilhados (MQOE), mais comum na bibliografia sobre estudos empíricos do modelo de Thirlwall. Como se pode ver, há inconsistências nos resultados, sobretudo na estimação da equação da demanda por importações. ${ }^{15}$ Em primeiro lugar, o parâmetro da sensibilidade da demanda por importações em relação à renda externa foi muito baixo, sobretudo

15 Contudo, optou-se por aqui manter e apresentar os resultados, ainda que inconsistentes. Isso segue as recomendações de Wooldridge (2006a; 2006b), para quem a inconsistência dos estimadores de MQOE é um bom teste para demonstrar a consistência dos modelos de $\mathrm{PD}$ e de EF, já que indica a presença dos fatores individuais que causam viés de variável omitida no modelo. 
se comparado aos resultados das estimações feitas por Pacheco-López e Thirlwall (2006) e por Cimoli, Porcile e Rovira (2010). Além disso, a sensibilidade das importações e exportações às variações do câmbio real não foi significativa na primeira equação e teve o sinal inverso ao esperado na segunda. Segundo Wooldridge (2006a, 2006b), a inconsistência dos estimadores de MQOE reflete a presença de correlação entre os regressores e efeitos fixos individuais não observados, que, por estarem inclusos no termo de erro da estimação, provocam viés de endogeneidade no modelo. Esse viés, para modelos de painel, é chamado de viés de heterogeneidade, provocado pela omissão de variáveis que controlam as características individuais de cada observação e que permanecem fixas ao longo do tempo.

No caso do presente trabalho, a baixa magnitude do estimador da elasticidade-renda da demanda por importações é causada pela existência de fatores não-observados específicos a cada país, que influenciam suas importações e que estão correlacionados com os seus produtos. Assim, esses fatores estão captando parte do efeito do produto sobre as importações. Como exemplos desses fatores, pode-se apontar para a política econômica adotada e a própria composição da pauta de importações de cada país. No caso da baixa significância da variável cambial, a análise individual dos países demonstra que há um contágio da amostra por parte das economias que utilizam câmbio fixo, já que, muitas vezes, a decisão da política cambial nesses países segue muito mais critérios políticos do que de estímulo às exportações.

Como forma de se controlar o viés de heterogeneidade, utilizou-se uma técnica mais refinada de dados em painel, que é a estimação pelas primeiras diferenças. Nessa estimação, a constante da equação de demanda por importações não foi significante, o que intuitivamente indica que os países da América Latina e do Caribe, em geral, não têm acesso a mecanismos de crédito e de financiamento externo para suas importações e dependem predominantemente do valor de sua produção interna para financiá-las.

Tentou-se aplicar em ambas as equações dummies para cada ano analisado. Contudo, a significância da maioria dos parâmetros dessas dummies não foi suficiente para justificar sua inclusão no modelo. Além disso, na equação da demanda externa por exportações, houve colinearidade entre essas dummies e a variável explicativa que mensura a renda internacional. Isso indica que a maior parte dos choques aleatórios que a demanda por exportações recebe decorre de variações no PIB dos países desenvolvidos, principalmente em períodos de recessão, tal como foi verificado por Cimoli, Porcile e Rovira (2010). 
Uma alternativa mais eficiente do que a estimação por primeiras diferenças, para dados em painel, sob a hipótese de exogeneidade dos regressores com os fatores individuais, é a estimação por efeitos fixos $(\mathrm{EF})$. Ao contrário do que ocorreu no modelo de primeira diferenciação, aqui as dummies temporais foram significantes, principalmente na equação de demanda por importações. Pôde-se observar uma tendência a partir dos anos noventa de elevação autônoma da variação das importações, não relacionada com fatores cambiais, ou de crescimento da renda dos países latino-americanos e caribenhos. O termo constante dessa equação continuou não sendo significativo, pelas mesmas razões descritas anteriormente.

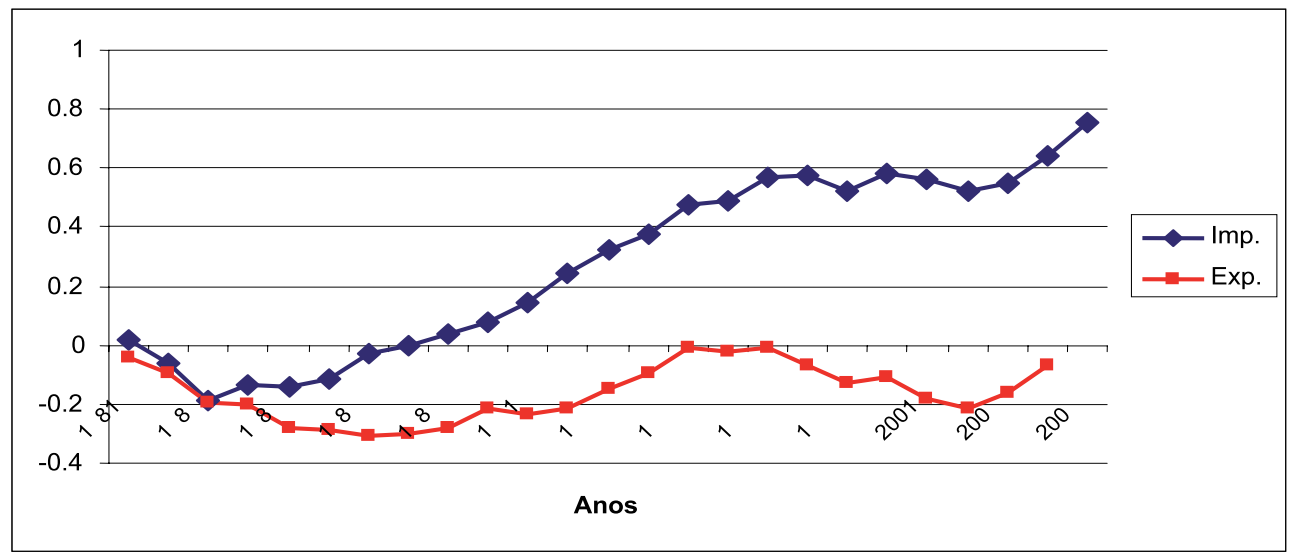

Gráfico 3 - Evolução dos Coeficientes das Dummies Anuais, Estimadas por Efeitos Fixos (1980-2005)

Fonte: Elaborado pelo autor.

$\mathrm{Na}$ equação de demanda por exportações, por outro lado, pôdese perceber que as dummies foram, em sua totalidade, negativas. Mediante a estimação de uma matriz de correlações, concluiu-se que essas dummies temporais estavam correlacionadas com a elasticidaderenda estrangeira por exportações. Isso significa que a maior parte dos choques exógenos recebidos sobre as exportações latino-americanas e caribenhas têm origem nas flutuações do PIB internacional. Por causa desses motivos, além do fato de que as dummies na equação de demanda por importações absorvem parte da significância do parâmetro da elasticidade-renda, optou-se por excluí-las das previsões realizadas sobre a tendência de crescimento econômico restringido pela balança comercial na América Latina e Caribe.

Cabe destacar que, tanto no modelo de primeira diferenciação como no modelo de efeitos fixos, o parâmetro da sensibilidade do câmbio real é significante, mas tem magnitude reduzida. Isto vai de encontro ao resultado do trabalho de López e Cruz (2000), e favorece as observações 
de Moreno-Brid e Pérez (2003) e de Pacheco-López e Thirlwall (2006). Certamente, isso foi provocado pela inclusão de pequenas economias na amostra, tais como as centro-americanas e as caribenhas, cujos governos têm menos graus de liberdade para exercer política econômica. Por outro lado, o sinal negativo do câmbio em todas as equações pode ser explicado pelos argumentos de López e Cruz (2000), para quem as políticas de desvalorização cambial, por encarecer a importação de bens de capital, provocar inflação e criar incertezas na economia, podem ter o efeito indesejado de contrair a demanda agregada.

Para comparar os procedimentos utilizados para estimar o modelo de Thirlwall para a América Latina e Caribe, foi utilizado o desvio da taxa de crescimento de equilíbrio da balança de pagamentos (yb) da taxa de crescimento média de cada país observada no período. Além disso, foi realizado o teste McCombie (PACHECO-LÓPEZ, 2005), que consiste em calcular a elasticidade-renda da demanda interna por importações consistente para o caso em que o crescimento real observado é igual ao crescimento compatível com equilíbrio na balança de pagamentos. Os resultados estão na Tabela 3.

Tabela 3 - Previsões e Desvios da Taxa de Crescimento de Equilíbrio em BP para os Modelos Estimados

\begin{tabular}{c|c|c|c|c|c|c}
\hline Método & $\mathbf{x}$ & $\boldsymbol{\pi}$ & $\mathbf{y b}$ & $\mathbf{y}$ & $\mathbf{y}$-yb & $\boldsymbol{\pi}^{*}$ \\
\hline PD (sem dummies) & $6.098 \%$ & 2.065 & $2.953 \%$ & $2.713 \%$ & $-0.240 \%$ & 2.248 \\
\hline EF (sem dummies) & $6.098 \%$ & 2.037 & $2.993 \%$ & $2.713 \%$ & $-0.280 \%$ & 2.248 \\
\hline
\end{tabular}

$\mathrm{x}=$ crescimento médio das exportações por país

$\pi=$ elasticidade-renda da demanda interna por importações

yb = taxa de crescimento compatível com equilíbrio na balança de pagamentos (ver (10))

$\mathrm{y}=$ taxa média de crescimento do PIB anual por país

$\mathrm{y}-\mathrm{yb}=$ desvio entre a taxa observada e a taxa prevista média de crescimento do PIB $\pi^{*}=\mathrm{x} / \mathrm{y}=$ elasticidade-renda da demanda interna necessária para $\mathrm{y}=\mathrm{yb}$

Fonte: Elaborada pelo autor.

Em seguida, foi analisada a dinâmica de longo prazo das elasticidades-renda das importações e das exportações para a América Latina e Caribe como um todo, sob a óptica das estimativas por primeiras diferenças e por efeitos fixos sem as dummies anuais. Tal procedimento foi utilizado em muitas das estimativas do modelo de McCombie e Thirwall para a região, como em Perez e Moreno-Brid (2003), PachecoLópez e Thirlwall (2006) e Pacheco-López (2009). Os resultados formam os Gráficos 4 e 5. 


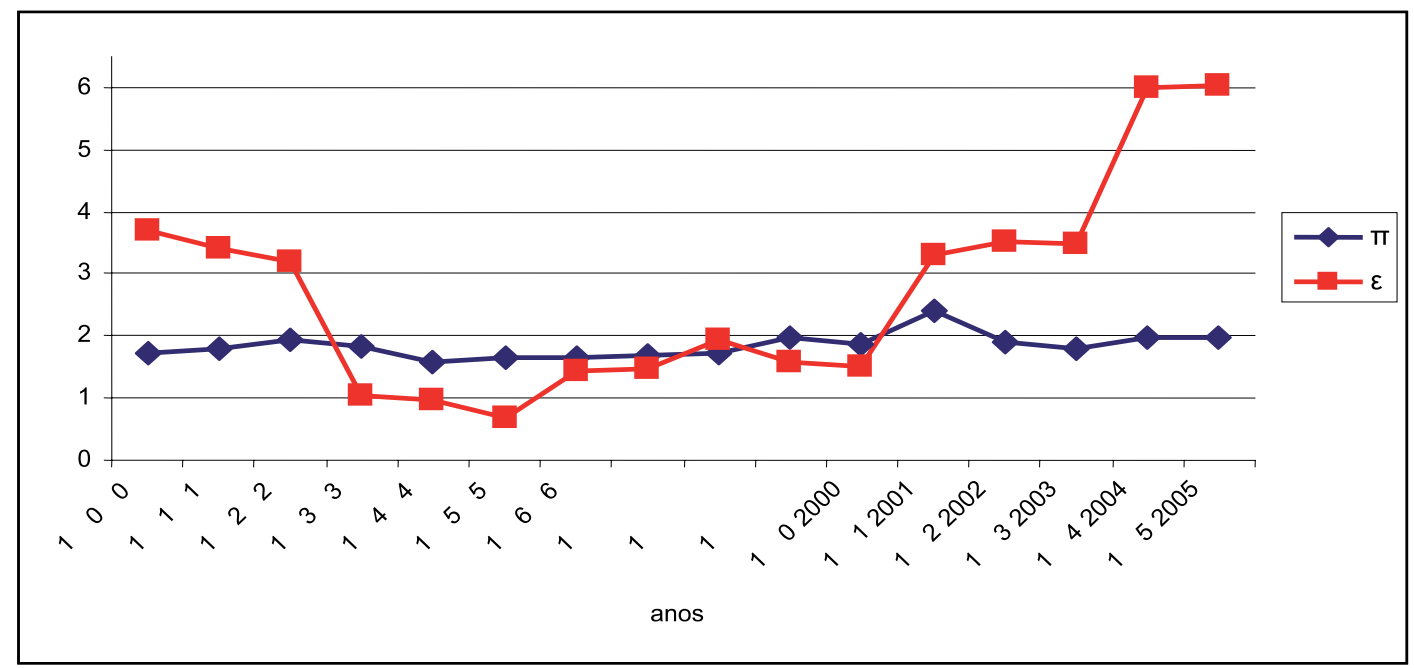

Gráfico 4 - Evolução das Elasticidades-Renda por Importações e Exportações na América Latina e no Caribe, por Primeiras Diferenças

Fonte: Elaborado pelo autor.

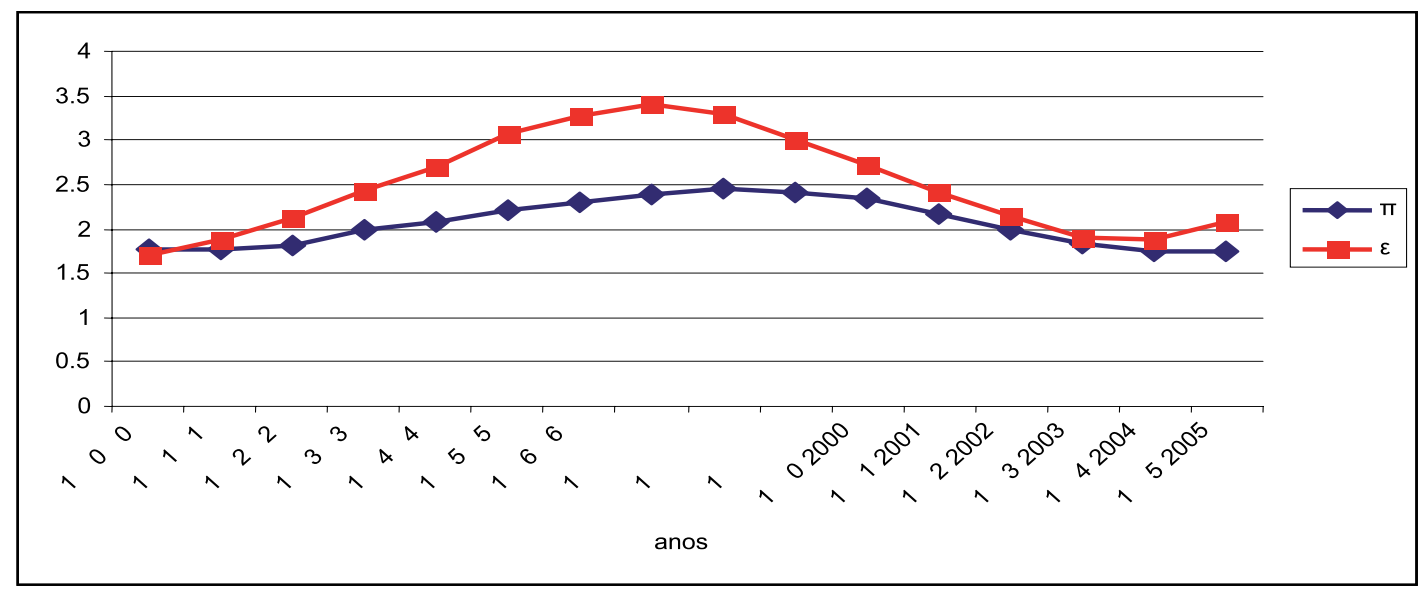

Gráfico 5 - Evolução das Elasticidades-Renda por Importações e Exportações na América Latina e no Caribe, por Efeitos Fixos

Fonte: Elaborado pelo autor.

A elasticidade-renda das importações manteve um comportamento muito mais estável do que a elasticidade-renda das exportações ao longo do período analisado. Moreno-Brid e Pérez (2003) apontam para três motivos que explicam esse fato. Primeiro, a adoção de políticas de estímulo às exportações. Segundo, mudanças na pauta de exportações dos países, para bens com maior valor e tecnologia agregada, isto é, com maior elasticidade-renda para a sua demanda. ${ }^{16} \mathrm{E}$ ainda, a pró-

16 Os autores destacam o caso da Costa Rica, que deixou de ser um exportador de bens primários para se tornar um exportador de computadores, ao receberem filiais de empresas estrangeiras da área via investimentos externos diretos. 
pria política de liberalização comercial pode afetar a elasticidade das exportações. Contudo, deve-se destacar que ambos os fatores são individuais para cada país; para a América Latina como um todo, não há evidências de que um desses três fatores seja predominante. ${ }^{17}$ Por outro lado, segundo Jayme Jr. (2003), a principal quebra da trajetória da elasticidade-renda das importações ocorreu no momento do colapso do modelo de desenvolvimento por ISI, no início da década de 80, e não com a liberalização comercial. Já o movimento de aceleração, ainda que suave, desse parâmetro durante os anos noventa em relação à década anterior está de acordo com hipótese da histerese dos efeitos de políticas econômicas restritivas sobre a valorização do câmbio real, o que incentivou importações.

Pelos valores dos coeficientes de elasticidade-renda da demanda por importações obtidos e da taxa média de crescimento das exportações, pôde-se realizar uma previsão da taxa de crescimento de equilíbrio em balança de pagamentos para cada período. Além disso, comparou-se essa taxa, obtida tanto pelos modelos de primeiras diferenças (PD) e efeitos fixos (EF) com a taxa real observada de crescimento econômico da América Latina e Caribe (y):

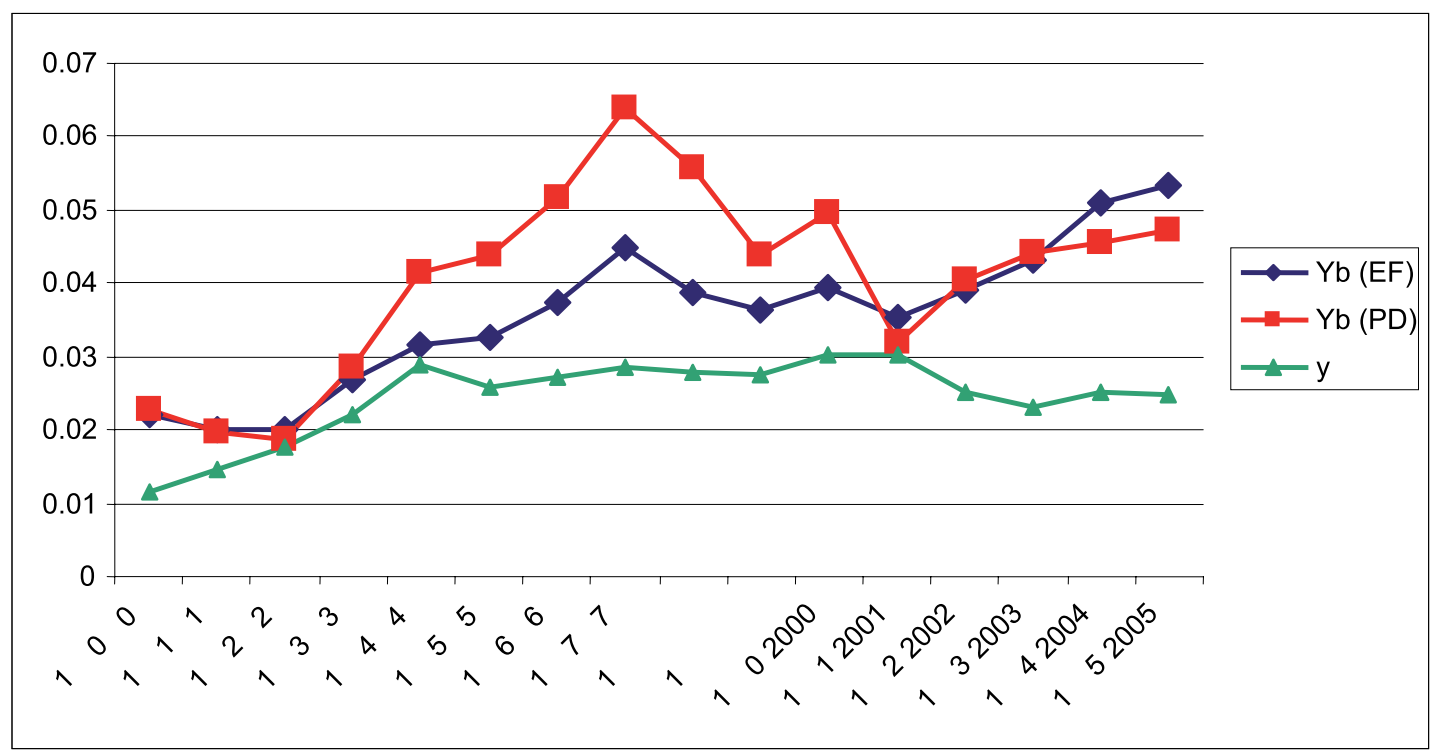

Gráfico 6 - Crescimento Econômico Médio Real e Compatível com Equilíbrio na Balança de Pagamentos, pelos Modelos de Primeiras Diferenças e de Efeitos Fixos Fonte: Elaborado pelo autor.

17 A maior suavidade da dinâmica dos parâmetros estimados por efeitos fixos pode ser explicada pela própria natureza desses estimadores, que são mais sensíveis a choques autônomos do que sobre as variáveis explicativas. Ou então, os estimadores podem estar distorcidos pela autocorrelação serial a qual são muito sensíveis. 
Como se pode ver, as estimativas realizadas por ambos os modelos convergiram nos períodos de 1980-90 a 1984-94 e de 1991-2001 até o presente, ao passo que, entre esses dois períodos, o modelo de primeiras diferenças exagerou a previsão de alta na taxa de crescimento de equilíbrio. Por outro lado, é visível que os países da América Latina e Caribe cresceram, nesse período, abaixo do seu potencial de equilíbrio em balança de pagamentos. Tal resultado também foi encontrado por Jayme Jr. (2003), que destacou a importância dos fluxos de capitais para explicar esse gap, e por Pacheco-López (2005).

Uma preocupação fundamental em pesquisas empíricas é procurar calcular estimadores que são estáveis frente a pequenas alterações na base de dados e à especificação do modelo. Em outras palavras, a realização de testes de robustez é importante para se conhecer a confiabilidade das previsões realizadas a partir dos parâmetros estimados. No caso da presente estimação do modelo de Thirlwall, que é baseada em séries macroeconômicas de países subdesenvolvidos, mais vulneráveis a choques e flutuações, é importante saber se os estimadores calculados podem estar sendo afetados por observações extremas nas variáveis independentes, os chamados valores outliers.

Para testar a estabilidade dos estimadores frente a mudanças nos valores outliers dos regressores, realizou-se o teste de Winsor (BARNETT; LEWIS, 1994). O método de Winsor, em resumo, procura suavizar os valores extremos sem descartar nenhuma observação do banco de dados. Esse teste consiste na criação de novas variáveis independentes para o modelo empírico, que são iguais às originais, mas com a diferença que o $1 \%$ dos maiores valores e o $1 \%$ dos menores valores dos regressores, para cada variável, são substituídos pelo valor adjacente não-extremo. Assim, roda-se novamente as mesmas regressões com as variáveis ajustadas (ou, segundo os autores que desenvolveram o teste, variáveis winsorizadas). Se os estimadores forem robustos, então seus parâmetros não deverão mudar muito em relação ao resultado das regressões originais.

Os resultados dos testes de Winsor para as equações de demanda por importações e por exportações da América Latina estimadas a partir do método de primeiras diferenças e de efeito fixo encontram-se nas Tabelas 4 e 5. 
Tabela 4 - Resultados do Teste de Winsor para a Demanda por Importações

\begin{tabular}{c|c|c}
\hline Variável & PD & EF \\
\hline Constante & 0.005 & $-24.891^{* * *}$ \\
& $(0.006)$ & $(0.855)$ \\
\hline w_ln_pib & $2.068^{* * *}$ & $2.043^{* * *}$ \\
& $(0.112)$ & $(0.038)$ \\
\hline w_ln_cambio_r & $-0.324^{* * *}$ & $-0.190^{* * *}$ \\
& $(0.038)$ & $(0.041)$ \\
\hline N. OBS. & 605 & 632 \\
\hline $\mathbf{R 2}$ & 0.460 & \\
\hline corr $(\mathbf{u} \mathbf{i}, \mathbf{X b})$ & & 0.907 \\
\hline
\end{tabular}

* * * Valor significativo a 1\%. ** Valor significativo a 5\%. * Valor significativo a $10 \%$. Fonte: Elaborada pelo autor.

Tabela 5 - Resultados do Teste de Winsor para a Demanda por Exportações

\begin{tabular}{c|c|c}
\hline Variável & PD & EF \\
\hline Constante & $-0.038^{* *}$ & $-49.528^{* * *}$ \\
& $(0.015)$ & $(1.488)$ \\
\hline W_ln_pib_ext & $3.563^{* * *}$ & $2.335^{* * *}$ \\
& $(0.479)$ & $(0.049)$ \\
\hline w_In_cambio_r & $-0.135^{* * *}$ & $-0.080^{*}$ \\
& $(0.041)$ & $(0.046)$ \\
\hline N. OBS. & 605 & 632 \\
\hline R2 & 0.097 & 0.010 \\
\hline \multicolumn{2}{c|}{ corr (u_i, Xb) } & \multicolumn{2}{|c}{} \\
\hline *** Valor significativo a 1\%. ** Valor significativo a 5\%. * Valor significativo a 10\%.
\end{tabular}

Fonte: Elaborada pelo autor.

Os resultados do teste de Winsor confirmam a hipótese de que a elasticidade estimada das exportações e das importações não varia muito com a suavização dos valores extremos do produto doméstico da América Latina e do exterior. Porém, o mesmo não pode se dizer dos parâmetros referentes ao câmbio real. Esses estimadores variaram mais em relação às variáveis winsorizadas, ainda que continuem significantes e com o mesmo sinal. Contudo, tal resultado pode ser explicado pelo fato estilizado de que grandes choques cambiais costumam afetar profundamente os fluxos comerciais dos países em um curto prazo. Como o câmbio é apenas uma variável de controle no modelo aqui adotado, que, fundamentado pela própria teoria, destaca o papel da 
elasticidade-renda da demanda por importações como fator que restringe o crescimento das economias subdesenvolvidas, as estimativas aqui realizadas para a taxa de crescimento de equilíbrio com a balança comercial podem ser consideradas robustas.

\section{Considerações Finais}

O presente trabalho procurou testar empiricamente a relação entre o crescimento econômico e o comércio internacional na América Latina e no Caribe no período recente. Ao contrário de estudos anteriores, que focalizavam sua análise empírica em séries temporais individuais para cada país, aqui procurou-se uma dimensão mais regional e agregada para o problema do crescimento econômico restringido pelos desequilíbrios comerciais. Por isso, testou-se o uso de técnicas para dados em painel, de modo a se obter parâmetros significantes em toda a região estudada, controlando-se os efeitos individuais. Com base nessa análise, que produziu resultados mais consistentes e robustos do que as estimativas por MQOE, pôde-se chegar a algumas conclusões.

Em primeiro lugar, em relação à elasticidade-renda das importações, a análise empírica demonstrou a existência de fatores individuais a cada país que influenciam a sua demanda por importações e que também estão correlacionados com o seu produto, provocando viés de endogeneidade nos estimadores de mínimos quadrados. Por isso, as técnicas econométricas para dados em painel foram importantes para o cálculo de estimadores consistentes. De acordo com as técnicas empregadas - primeira diferenciação e efeitos fixos - a elasticidaderenda das importações latino-americanas é compatível com um nível médio de crescimento com equilíbrio na balança de pagamentos de cerca de 3\% ao ano. Ainda que esse valor seja superior ao crescimento médio da região no período de análise, é um patamar muito inferior ao crescimento observado em outros países em desenvolvimento como os asiáticos, e certamente é inadequado para que os países da região superem sua condição de subdesenvolvimento. Além disso, as variáveis dummies temporais no modelo de efeitos fixos revelaram uma tendência de elevação autônoma das importações a partir dos anos 1990, de modo que as importações, a partir desse ano, cresceram mesmo em um ambiente de estagnação do produto. Por fim, a dinâmica de longo prazo da elasticidade-renda das importações se mostrou estável de acordo com todos os métodos utilizados para a estimação. De acordo com a bibliografia estudada, tal como em Jayme Jr. (2003), o aumento generalizado desse parâmetro ocorreu no início da década de 1980, 
com o colapso do modelo de ISI, e não com o processo de liberalização comercial iniciado no final da mesma década.

No que diz respeito às exportações, as estimativas indicaram que a elasticidade-renda da demanda externa é maior do que a da demanda interna por importações. Isso é um sinal de que a demanda internacional pelas exportações latino-americanas é muito sensível às variações da renda dos países desenvolvidos, sobretudo nos tempos de recessão, tal como foi verificado por Cimoli, Porcile e Rovira (2010). Em relação à sua dinâmica de longo prazo, a elasticidade-renda das exportações mostrou-se mais volátil do que a das importações. A literatura estudada, como Moreno-Brid e Pérez (2003), aponta para várias hipóteses para esse resultado, sendo que a maior parte delas refere-se a efeitos de políticas pró-exportadoras e de mudanças qualitativas da pauta de produtos em países específicos. Todavia, para a América Latina como um todo, não há um motivo predominante aparente, e esse pode ser um tema a ser explorado em pesquisas futuras.

Por fim, as estimativas demonstraram que o câmbio real tem efeito significante sobre as importações e exportações latino-americanas, mas a magnitude do seu estimador é sempre reduzida e com pouca robustez, ou seja, é muito sensível a valores extremos contidos na amostra. Segundo Moreno-Brid e Pérez (2003) e Pacheco-López e Thirlwall (2006), isso é um reflexo de fatores como o efeito de economias pequenas, em que os governos têm limitados graus de liberdade para exercer política cambial, de países com câmbio fixo, que reduzem a variabilidade dos dados coletados, e do efeito dos movimentos de capitais sobre o câmbio, que costumam ser muito mais intensos do que os fluxos comerciais. Além disso, a própria teoria da lei de Thirlwall assume que os fatores reais são mais importantes para a determinação dos fluxos comerciais do que o câmbio real, no longo prazo. Também destaca-se que o sinal do parâmetro do câmbio real é negativo tanto para as importações como para as exportações, o que corrobora a hipótese de López e Cruz (2000), de que choques cambiais intensos, de qualquer sinal, costumam provocar flutuações do preço dos bens de capital e incertezas na economia, o que inibe investimentos e prejudica o crescimento do produto.

Um ponto que se destaca para pesquisas futuras é compreender por que a América Latina e o Caribe cresceram, ao longo de todo o período de análise, abaixo do que foi estimado como a taxa de crescimento compatível com equilíbrio na balança de pagamentos. Por hipótese, esse problema pode estar relacionado com os ciclos de liquidez da economia internacional, ou pelo impacto que as reformas institucionais realizadas ao longo desse período tiveram sobre o ânimo dos empresários em investir no setor produtivo. 


\section{Referências}

BAER, W. Neo-liberalism in Latin America: a return to the past? Financial Markets and Portfolio Management, v. 16, n. 3, p. 309-315, 2002.

BARNETT, V.; LEWIS, T. Outliers in statistical data. 3. ed. Chichester: Wiley, 1994.

BENECKE, D.; NASCIMENTO, R. O consenso de Washington revisado. Cadernos Adenauer, v. 4, n. 2, p. 13-32, 2003.

CARDOSO, E.; HELWEGE, A. Da substituição de importações à liberalizaçao do comércio. In: CARDOSO, E.; HELWEGE, A. A economia da América Latina. São Paulo: Ática, p. 87-123, 1993.

CIMOLI, M.; PORCILE, G.; ROVIRA, S. Structural change and the BOP-constraint: why did Latin America fail to converge? Cambridge Journal of Economics, v. 34, n. 2, p. 389-411, 2010.

COMISIÓN ECONÓMICA PARA AMÉRICA LATINA Y EL CARIBE. Anuario estadístico de América Latina y el Caribe, 2006. Disponível em http://websie.eclac.cl/anuario_ estadistico/anuario_2006/. Acesso em 10 dez. 2007.

COUTINHO, L. A fragilidade do Brasil em face da globalização. In: BAUMANN, R. O Brasil e a economia global. Rio de Janeiro: Campus, p. 219-238, 1996.

FRANCO, G. O desafio brasileiro: ensaios sobre desenvolvimento, globalização e moeda. São Paulo: Editora 34, 1999.

HARRISON, A. Openness and growth: a time-series, cross-country analysis for developing countries. Journal of Development Economics, v. 48, n. 3, p. 419-447, 1996.

HARROD, R. International economics. Cambridge: Cambridge University Press, 1933.

HOLLAND, M.; VIEIRA, F. V.; CANUTO, O. Economic growth and the balance-ofpayments constraint in Latin America. Investigación Económica. v. LXIII, n. 247, p. 45-74, 2004.

INTERNATIONAL MONETARY FOUND. World economic and financial surveys: world economic outlook database october 2007 edition. Disponível em http://www.imf.org/ external/pubs/ft/weo/2007/02/weodata/index.aspx. Acesso em 10 dez. 2007.

JAYME JR. F. Balance-of-payments-constrained economic growth in Brazil. Brazilian Journal of Political Economy, v. 23, n. 1, p. 62-84, jan./mar. 2003.

LIZARDI, C. G. Thirlwall's law with an emphasis on the ratio of export/import income elasticities Latin American economies during the twentieth century. Estudios Económicos, v. 21, n. 1, p. 23-44, 2006.

LÓPEZ, J.; CRUZ, A. "Thirlwall's Law" and beyond: the Latin American experience. Journal of Post Keynesian Economics, v. 22, n. 3, p. 477-495, 2000.

MCCOMBIE, J. S. L.; THIRLWALL, A. The balance-of-payments constraint as an explanation of international growth rate differences. In: MCCOMBIE, J. S. L.; THIRLWALL, A. Economic growth and the balance of payments constraint. New York: St. Martin's Press, 1994.

MORENO-BRID, J. C.; PÉREZ, E. Trade liberalization and economic growth in Central America. Cepal Review, n. 81, dez. 2003. 
PACHECO-LÓPEZ, P.; THIRLWALL, A. Trade liberalization, the propensity to import and growth in Latin America. Journal of Post Keynesian Economics, v. 29, n. 1, p. 41-66, 2006.

PACHECO-LÓPEZ, P. The effect of trade liberalization on exports, imports, the balance of payments and growth: the case of Mexico. Journal of Post Keynesian Economics, v. 27, n. 4, p. 595-619, 2005.

. Los efectos de la liberación comercial en el crecimiento económico y la balanza de pagos en América Latina. Investigación Econômica, v. 68, n. 267, p. 13-49, 2009.

PREBISCH, R. Crecimiento, desequilibrio y disparidades: interpretación del proceso de desarollo económico. In: GURRIERI, A. La obra de Prebisch en la Cepal. México: Fondo de Cultura Económico, 1982a. [Cap. 2].

. El desarrollo económico de la América Latina y algunos de sus principales problemas. In: GURRIERI, A. La obra de Prebisch en la Cepal. México: Fondo de Cultura Económico, 1982b. [Cap. 1].

. Problemas teóricos e prácticos del crecimiento económico. In: GURRIERI, A.

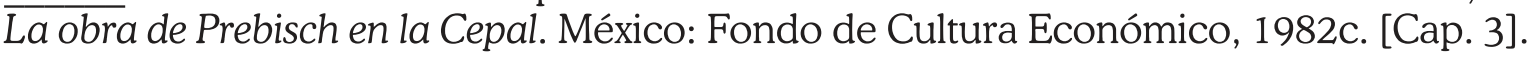

UNITED NATIONS. UNSD statistical databases 2007. Disponivel em http:/unstats.un.org/ unsd/databases.htm. Acesso em 13 dez. 2007.

WILLIAMSON, J. The Washington consensus as policy prescription for development. In: PETERSON INSTITUTE FOR INTERNATIONAL ECONOMICS, Washington, DC, 2004. Disponível em http://www.iie.com/publications/papers/williamson0204.pdf. Acesso em 21 nov. 2007

WOOLDRIDGE, J. M. Econometric analysis of cross section and panel data. Cambridge: MIT Press, 2006a.

. Introdução à econometria: uma abordagem moderna. São Paulo: Thomson Learning (Pioneira), 2006b.

Recebido em: 10/07/2009.

Aceito em: 10/06/2010. 